\title{
Impact and OperaScotland, the listings and archive website
}

Peter J. Fraser, lain S. Fraser and Stephen Fraser

This is the Author Accepted Manuscript. The final published version is available at Emerald via doi: 10.1108/AAM-08-2016-0013 


\section{EEmerald Arts Marketing}

Impact and OperaScotland, the listings and archive website.

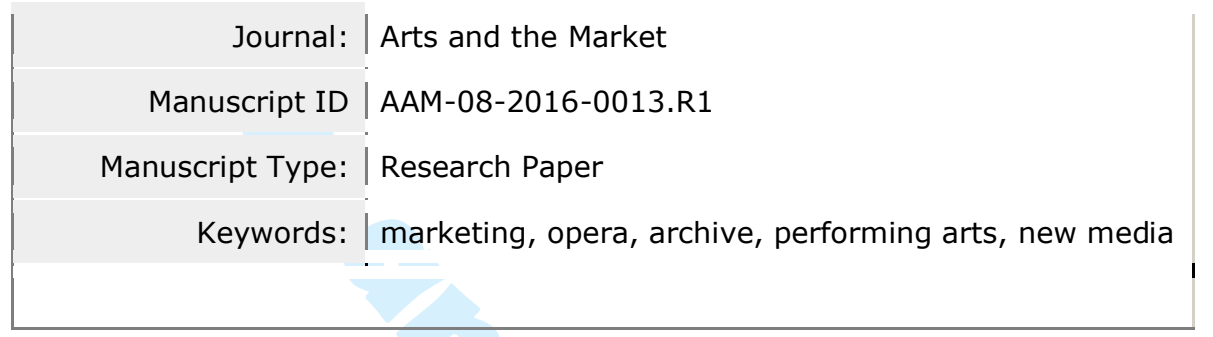


Impact and OperaScotland, the listings and archive website.

\begin{abstract}
Purpose - to reflect on the development of a performing arts archive website, exploring mainly qualitative measures of impact in relation to the marketing and promotion of opera and understanding of opera history.

Design/methodology/approach - sets out a reflectivecasestudy in relation to a social enterprise in the arts.

Findings - confirms that development of a specialist or niche website is a slow process requiring significant effort and resource. Promotion draws on a variety of activities including networking, face to face selling, word of mouth and use of new media.

Practical implications - a case study offering insights and potential learning point for those considering such projects or in similar positions.

Originality/value - summarises participant experience of launching a hobby website in the cultural sector. Finally, examples of impact are identified and discussed to indicate directions for further development and research.

Keywords - marketing impact, social enterprise, performing arts history; opera marketing, cultural community, qualitative research

Paper type - research paper

\section{Introduction and context}

Three opera fans embarked some years ago on the creation and development of OperaScotland ('OpScot'), a website intended to list and promote opera and opera-related activity in Scotland. Launched in 2009, the website is one of performance record. It has been described as 'a labour of love' (Brooke 2014). It offers no opera in the form of performance, video, audio or ticket sales, but provides an archive and listing or promotional resource 'free' to those who do. Normally included are cast details, publicity stills and programme cover where available. Sometimes there are also performance reviews. All this listings data rolls over into the archive when the performance date has passed. Simultaneously with production of current listings, efforts are made for the years before 2009 to locate and upload archive content. This tends to take the form of a particular project, for example to identify all past performances of a specific work.
\end{abstract}

What parallels are there? The Internet Movie Database (IMDb), UK developed but now owned by Amazon, is well known not just to film buffs but to a wider public. Many had wondered why there was nothing similar for the theatre-loving public. In fact, the need for performing arts archives has been long recognised (Reason 2003b), with discussion about online systems among archivists in UK and Ireland having run for at least 14 years. Perhaps fortunately, at the outset OperaScotland co-founders were in ignorance of thiswidercontext. Their initial online searches had failed to turn up much more than opera and theatre databases focused on current activity of a single company with scant attention to archives. Despite increased awareness of the international operating environment, there still appears to be only limited development to meet these needs.

Elsewhereintheliveperformingarts the co-founders have become aware of AusStage, a comparatively large-scale project funded by the Australian government and which was initiated in 2000 (Stone 2004; Bollen et al. 2009). AusStage incorporates a wide range of performing arts data, opera being a small part of its coverage, and is much more sophisticated. At the time of writing it is many times the size of OpScot andtherefore offers 
greater potential to the researcher. Another Antipodean project, Theatre Aotearoa Database (TADB), is akin to AusStage in some of its ambitions but was started in 2004 and is a much less well-resourced New Zealand enterprise (Warrington 2012). Here in the UK another example in the same genre is the Staging Beckett database at Reading. This was developed to incorporate details of all professional stage performances of works by Samuel Beckett in the UK and Ireland. What here sounds like a specialist database was deliberately designed with the potential for wider application. A Pantomime database at the V\&A was started several years ago and focuses on logging all current work in that genre. Sensibly perhaps, no attempt is being made to attack the huge historic archive in that art form. By comparison, for OpScot it is the tracking downof historic data that presents the greatest challenge.

These projects do not seem to be unusual. Theatre-goers across all genres get used to finding their experience and the cultural events forming part of their identity being forgotten in a million acts of negligence. Performance records are neglected or erased. Artistes die -or moveontomorehighlypaidemploymentelsewhere- and companies fail. Obviously, identifying and listing performers and their performances does not recreate the past. In any case, archives represent detritus, not completeness (Reason 2003a). Listings are drawn from a wide range of sources and archives and even at their best and most accurate can represent output in only a very limited way. Yet however basic and incomplete the information contained in such data, 'performing arts archives make it possible to preserve the memory of artists, movements and performances' (Marini 2008).

But the other main difficulty facing all these developments lies as much in relation to input as the database design. What all these performing arts archive databases currently have in common is that they require information about the performance and casts to be copy-typed in from a programme or other authoritative source. It is hard to see how such a process might be automated given that there are huge variations in the names of works, roles and even performer names. A significant amount of tacit knowledge is needed for this activity to work effectively, makingdevelopmentsomethingofacraftprocess.

Furthermore, what academic literature currently exists seems to consist of a mainly technical nature pertaining to databases and there is little about some of the more general business issues or indeed in demonstrating potential and impact.

\section{Literature}

From an academic perspective, many business issues seem potentially relevant: literature related to social enterprise and social marketing (Shaw 2004); to trial, error, effectuation and 'muddling through' (Sarasvathy 2012; Ries 2011); entrepreneurial and small business marketing (Gilmore 2011); branding and positioning for arts and non-profit organisations; and audience development (Slater and Armstrong 2014) are all likely to contribute insight.

Most relevant for the purposes of this article are those concerned with online resources in the arts and humanities, and Arts Marketing. Arts marketing literature in particular has generally been published across a wide range of academic journals. Rentschler and Kirchner, in conducting an analysis of 20 key journals in management and marketing and reviewing publication elsewhere, highlighted the wide range of scholars and policy makers who are citing articles in this area (Rentschler and Kirchner 2012). O'Reilly also drew attention to the wide-ranging nature of what was considered a 'substantial body' of 'arts literatures' and went on to highlight a number of gaps. Several of these appear to be related to the nature of arts themselves (O'Reilly 2011). The author highlights among other areas for fruitful inquiry a 
framework for the understanding of arts consumption, arts consumption communities, and the connections between arts marketing, the creation and cultural industries, cultural economics and cultural policy. OpScot is operating in ways which enhance the development of a particular niche in the arts consumption community.

Increasingly OperaScotland attention has turned to the needs of user segments, in particular various academic communities who are likely to be the 'heavy users' of the site, staying for longer periods of time. The limited availability of journal material on traffic analysis offers a clear research gap, particularly for a niche site. There seem no obvious comparators or benchmark websites. When approached, several other website owners declined to reveal their own performance figures, even on a basis of mutual exchange. Google Analytics used to offer opportunities to look up performances data for exemplars in different sectors but this service has been withdrawn. Some online sites claim to generate performance figures for any website, but on the basis of their profiles for OpScot, these are worthless.

Plaza et al offer a methodology using Google Analytics and based around a particular case, that of a cultural tourism site scholars-on-bilbao.info (Plaza 2011) and subsequently troka.com for Adventure Sports Tourism (Plaza et al. 2011). She and her colleagues stress the focus on methodology and call for more experiments with different data sets so that this methodology has more general value.

\section{Research Questions}

However, in this particular paper the focus is on the critical issue of impact. Impact has become of increasing importance to academics in the light of new requirements underpinning the Research Excellence Framework. In this context, impact has been broadly defined as 'an effect on, change or benefit to the economy, society, culture, public policy or services, health, the environment or quality of life, beyond academia' ("REF impact" 2016).

Most approaches to research move from an abstract paper or concepts to finding something in the world to which it is relevant. In the case of OperaScotland there is, starting from nothing, now a developing website, something that is already a presence in the world. The chosen approach is not unlike that of grounded theorv (Glaser and Strauss 1967). Research themes will arise, and eventually with it some insights and theory. Questions continue to emerge from material as it accumulates and as the community of interest grows.

Moving to the specific case of OperaScotland, some preliminary questions arising might be:

- What qualitative measures of impact might be useful?

- How else might impact be identified and evaluated?

- What in the light of these are the implications for the managers of OperaScotland?

\section{Research methodology}

The mixed methods approach adopted included literature review, archive searches, plus a number of informal in-depth interviews and conversations. Other evidence to support this narrative of the project is assembled from a variety of sources including participant observation by one of the co-founders as well as Google Analytics data. Material and comment is also drawn from engagement with the Association of Performing Arts Collections (APACs), blogs, new media and email activity.

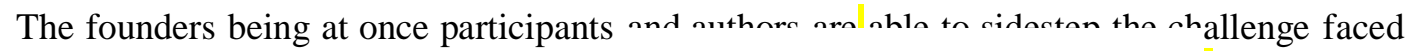
by other researchers of gaining access. Ethical issues are frequently discussed. The next question might address objectivity - which in close relationships above others is hardly 
possible - or the difficulty of thinking beyond day to day activity, the 'living present'. It is assumed that action, and continuous reflection on this, is at the base of what it means to make sense of one's relating with others. Elias summarises this paradox as simultaneous involvement and detachment. The aim is to maintain a perspective of emergent inquiry balancing engagement and detachment (Elias and Dunning 1986; Elias and Schröter 1994; Keegan 2011).

Keegan summarises current research practice by saying "We are more like naturalists, working in a world of shifting relationships, changing perception, contextual understanding. We can never be outside the research situation." (Keegan 2011:32) And research here is "an on-going and creative process of action learning" (Keegan 2011:31). The co-founders are constantly posing to themselves the questions 'How are we doing?' and perhaps more important theissueofnextsteps: "What do we do now?"

\section{Performance data}

By its nature, database management is repetitive and even with an underlying interest in the content, the work can quickly come to seem tiresome.On OpScot, for a performance of a single opera the input process may take as long as an hour to complete though the exact time needed will depend on how much of the content has been entered before, the number of performers, and so on. The nature of the process has changed somewhat over time. As content grows, the time taken for checking and input has increased. Attention must now be directed to improving efficiency.

There has been no grand plan or strategy. In 2007 a decision was taken to start work and see where it led (Fraser 2005). This approach is partly influenced by ideas drawn from complexity (Stacey and Mowles 2016). Such a style would tend to downplay any planning other than the short term and emphasising gesture and response, trial and error. The dominant approach in the literature of setting detailed long term targets is instead taken with a pinch of salt. A focus on continuously improving the database in content and features has been the priority. The value of such emergent and indirect strategies has been highlighted in recent years (Kay 2011)

Over time the database has gone through two major redesigns and a very large number of tweaks and small variations. In the process of developing the database fields it was a surprise to discover how many variantswereneeded - venues, performers, and the works themselves may all have changed their names or have versions in different languages. Some characters with the same name appear in different operas, and so on. So from early on, the need for great care was understood. This is not an open database designed like Wikipedia for ease of access and which could readily be made available for strangers to enter data directly.

How is performance data obtained? In relation to historical performances, the press represents a fundamental source. Online searching saves much time but coverage is by no means universal. Some periodicals are not yet digitised, or available only behind paywalls, while others are scattered across several different electronic databases. Microfilm copies of newspapers have also proved an essential resource.

Sources drawn upon include the British Newspaper Archive Online; the Scotsman; The Guardian; The Times and the Google News Archive. Details have also been abstracted from programmes and playbills in the online database of the Scottish Theatre Archive at Glasgow University, and the Scottish Theatre Programmes database in the National Library of 
Scotland. The work involved is often of the sort - substantialand tedious-recognized by all researchers. In relation to one particular example of a mini-project establishing performance data for a short-lived opera company, the owners drew upon a prospectus in Dundee Public Library and later upon posters in Manchester Central I ihrarv and Central I ihrarv Liverpool. None of these hard copy itemsof ephemera were identifiable from the catalogues of the relevant libraries.

Perhaps it is easier to find detail for contemporary work. For forthcoming performance, managers of a company will normally supply a range of detail often including cast members and their photographs. Some organisations have been reluctant to supply this information though over time this has improved.

\section{Development of OperaScotland}

Website design and development is a process held to require significant resources and a wide range of skills. In this case, however, the initial phases were pursued on a shoestring. This article covers a period of more than seven years from 2007 - the year when the idea was first discussed (Fraser 2005). Early planning of the project in relation to research, start-up phases, or participant roles could best be described as emergent, with the emphasis on effectuation rather than causation (Sarasvathy 2012; Ries 2011).

The OperaScotland brand name is both a strength and a weakness. The site is still confused with that of Scottish Opera. Despite a strapline intended to make the focus clear, the owners have been approached by singers looking for employment. On other occasions emails from relatives have communicated the deaths of singers listed on the site, or asking if OpScot holds specific video or audio recordings. More positively, the generic nature of the website brand name is also in line with the 'unimaginative but accurate' description recommended for a successful Arts and Humanities website (Warwick et al. 2008). Almost anyone working online and searching for 'opera' linked to 'Scotland' is likely to find the site.

Promoting for growth and impact

What is impact and how would awareness be maximised as the site amasses content? In addition to the OperaScotland website, the founders operate a parallel Facebook page; and a linked Twitter account is used both independently and also automatically as Facebook entries are made. New media - currently Facebook, Twitter and YouTube - are used to promote, to build community and encourage visits to the OperaScotland site.

Bauer et al (2002) argue that web activity is most suited to established face-to-face relationships where trust already exists. OperaScotland is obviously niche, one amused reaction being 'super niche' (Fraser 2005). Not all founders were at the outset well known in the opera community so promotion and networking was critical. Constrained by time and money they set out to identify allies and potential allies, building relationships and rapport, both conventional and face-to-face and online activity (Shaw 2013).

Traffic: engagement

What is the potential market and what traffic might it generate? There is evidence that 2-3\% of a population are likely to be opera-goers (Agid and Tarondeau 2010). Set against a Scottish population of 5,295,000 at the 2011 census, this broadly indicates something in the region of 100,000-160,000. Opera relays shown in cinemas may enhance this in time to come. 
Another approach was target based, to explore what traffic levels might attract advertisers and hence income. Initial advice was that to appeal to advertisers the site would need to draw 5000 visitors per month. Existing traffic is running between 2500-4500 visitors per month. However, more detailed comments later suggested the target numbers need to be ten times this level.

By end of January 2017, Google Analytics evidence on the site demonstrated that over almost seven years there has been total lifetime traffic of 140,500 'unique visitors' giving 190,000 'visits', with an annual total 'unique visitors' of 34,000. Traffic is seasonal, with a peak in August and a trough in December. How good is this for such a specialist site?

Impact: quantitative measures

The emphasis in this paper has been on qualitative evidence of impact. However throughout the existence of OperaScotland, activity has grown to the extent that by 31 January 2017 there were 1370 'follows' on Twitter and 2400 'likes' on Facebook.

$\begin{array}{lcc}\text { Opera-related Company } & \begin{array}{c}\text { Twitter } \\ \text { 'follows' }\end{array} & \begin{array}{c}\text { Facebook } \\ \text { 'likes' }\end{array} \\ \text { Opera North } & 30700 & 10900 \\ \text { Scottish Opera } & 19100 & 7000 \\ \text { OperaScotland } & 1370 & 2400 \\ \text { Opera Bohemia } & 1212 & 1200 \\ \text { Edinburgh Studio Opera } & 608 & 890 \\ & \text { As at Jan } 2017\end{array}$

OpScot presence in these new media is not insignificant: but it is hard to judge how this represents success or how far a comparison with major performing companies is helpful.

A flavour of Google Analvtics data can be obtained from Appendix 1. which presents some features of performance over a three-year period 2014-2017. These include number of visits; pages viewed; average time spent on the site; and geographical segmentation of the visitors. More detailed quantitative analysis is scheduled.

Website content has grown to contain 480 theatres \& other venues; 600 operas; and over 11,000 people (i.e. performers and other named individuals). Many of the people entered are literally just 'names', as the earliest performance listed in OpScot dates from 1755. Most historical performers are not just dead but long forgotten. To populate all their entries with supporting biographical information represents an impossible task. A high proportion of fields are mainly blank, offer little reward to the visitor and may account in part for the high 'bounce' rates shown in traffic analysis.

Impact: qualitative evidence and personal testimony More of those the owners meet now say they have heard of the website and have used it. Promoters and performers who are met at opera performances sometimes express pleasure and thanks.

The owners are all too aware of many weaknesses and gaps in the performance record. Users have commented for example that there is always scope to improve site ease of use. 
However, there has been advice that OpScot is 'very clearly coming across as a voice and [an] authoritative voice'(Rudman 2014). Other positive comments include:

"...Opera Scotland.org a fascinating compendium of the art form's past, present and future north of the border..." (Clark 2016)

"A unique and valuable resource for anyone who cares about, or who is involved in, both the past and the future of opera in Scotland." (Dean 2014)

"May I wish you all the best with your mammoth undertaking, on which I appreciate you have been working for some time now; not only is it very interesting and productive, but I am sure that it will eventually become a great source of reference for students, academics, and theatre/opera buffs alike." (Paul 2015) "I have found [the website] extremely useful - and amazingly accurate. It provides a fascinating and impressive record of Opera in Scotland over the years, documenting its achievements with meticulous precision." (Hall 2014)

"I have only just discovered your terrific site. How fantastic to see this resource of opera in Scotland. Congratulations." (Curran 2016)

"You are doing wonderful things for opera in Scotland."(Carson 2016)

The owners will continue to capture evidence of impact in the form of comment and testimonials from users. Occasional emails have highlighted errors and omissions, and also provide further evidence of engagement.

What are other responses to the site? In summer 2013 there were some more emails, including queries from university students working on theses and dissertations. Presumably there is a parallel with the 'tip of the iceberg' metaphor: these are likely to be indicators of more widespread awareness, interest and word of mouth. Just as with documents, online databases hold potential to spark many responses. But it can inferred that there must be conversation of which there is no knowledge (Donaldson 2007). Yet it seems important to try to respond, to foster opportunity for communication.

As the number of names in the database rises, so does the potential for this material to be of some interest for genealogical research. One 'family research' email asked for further information about an opera singer and read in part:

My mother (95) has very fond childhood memories of her Auntie and would love to see a photo of her, if one can possibly be found. I have recently discovered their granddaughter, living in Australia, but she has no photo of [her] either, but would dearly love to find one.

Some of the queries have been autobiographical in nature. One of the replies to an email about performance details provoked a response that reads in part:

I had thought it was during the Festival but I see it was during the Spring. It was 40 years ago and I got that bit wrong (I remember the weather being warm because after the performance, having long since missed the last train home, I had to spend overnight in the large waiting room at Waverley Station and although it was uncomfortable, it was not cold).

Some music critics in newspapers and other periodicals have made reference in their notices to material which seemed available only to someone searching the OpScot site, or more likely from reading the notes on historical performance supplied by OpScot in Scottish Opera programmes. Several items for sale on eBay, notably photographs of singers, have been described using information from the site. 
Then there was what turned out to be a longer-running inquiry from Ian Brooke, Programme Editor for Scottish Opera. In May 2013, an incoming email contained 9 queries in preparation for a forthcoming $50^{\text {th }}$ anniversary volume on the history of Scottish Opera. In return for a substantial amount of work, credit was given through a mention in the foreword (Brooke 2013).

A more frustrating experience took place at a research conference where a speaker was summarising findings from their recent book. In private conversation afterwards, the speaker revealed that they had not only heard of the site but had used it 'quite a lot', to the extent, they said, that they felt guilty about it. Skimming the scholarly book some days later, there was no mention of the site nor indeed of any other electronic resource. Operators of AusStage, a much larger and longer established performing arts database, have stressed the significance to them of academic reference in proving evidence of impact and value. Accordingly OpScot will soon have an enhanced section on academic referencing.

Impact: archive materials

All three founders have tended to buy and keep programmes for events attended, including opera. As with avid lifetime arts and sport attenders, for many people storage and information retrieval becomes problematic (Higgins 2011). With the death of an owner, meaning is lost also. As their monetary value, with rare exceptions, is negligible it seems that almost all are then sent for recycling. To put this in context, collections of such ephemera in libraries, both national and local, general and specialist, are uneven to say the least. A few libraries collect ephemera seen as of national importance, but most demonstrate minimal interest. Performing companies offervariableservice: the archive of one significantUK company is closed indefinitely, while another employs five archivists.

More recently OpScot received offers of material, gratefully accepted as filling some of the many gaps in the OperaScotland collection. One writer offered us a dozen programmes from Glasgow Grand Opera for performances in which her late uncle appeared. A more substantial gift consisted of 27 box files full of programmes. Thirdly, a correspondent who had been a manager at the company during the early days of Scottish Opera very helpfully offered some significant promotional and newsletter items. A fourth offer resulting from a house clearance consisted of correspondence and photographs of an important pre-war singer. These unsolicited offers - from people who have found the site - again offer evidence for OpScot 'presence', 'awareness' and impact. However, the implications for curation of all this new material are considerable. Greater attention will have to be given to storage and preservation and to the ways in which the archiving process can be made more professional.

Co-creation and the Opera Community

Over the last few months the owners seem to have moved from a position when they have been approaching small opera groups and societies for information, to one where groups have spontaneously been seeking support.

One of the key areas for developing a process of community, the owners thought, should lie in linking to other groups, and other sites. Academicresearchgroupsandlibrariesofferclear potential(Warwicketal.2008). The linking process has turned out to be slower and more challenging than expected. However it is hoped that collaboration with AusStage and other database projects may become an important feature of work, with in the longer term perhaps some degree of interoperability between OpScot and others. 
Impact: income

Income-earning and fund-raising activities are on the agenda and will have to be developed significantly in order to cover operating costs and site enhancement, although the priority remains to build traffic, quantity and quality of content, service credibility and reputation.

There has been some benefit in kind; several companies have started offering tickets in exchange for a review of their production(s) on the OpScot website.

Some modest revenue has been received from Google AdSense, talks, and use of an archive photograph in a TV programme. An OpScot photograph, a 1906 postcard of the soprano Agnes Nicholls, was used to illustrate a BBC2 Scotland programme about Scotland's 191418 naval war. OpScot was listed in the end credits along with the Imperial War Museum, V \& A and many another far better established museums and archives (Twaddle 2015).

A donation button has been added to the site, offering users the opportunity to place a value on benefit received.

Carl Rosa: Touring Opera in Scotland 1874-1899, was published on Kindle in June 2013. Other follow-up publications, including for reputational purposes writing for academic journals, are also on the agenda.

\section{Promotion and traffic-building}

OperaScotland has been promoted using a wide range of approaches, both traditional and modern. Initial activity concentrated on networking, PR, and the distribution of leaflets and business cards as well as the application of new media such as Twitter and Facebook.

Starting in 2011 with Rigoletto, 34 notes on historic performance in Scotland have been researched and incorporated in Scottish Opera programmes, adding value to the programmes as well as raising awareness of OpScot.

Part of this background research involves identifying the date of first Scottish performance for a particular operatic work. In the process, dates for several premieres have been discovered that were earlier than those previously accepted or cited in reference books. This is quite specific evidence of impact. In addition, OpScot has received several requests from companies asking for dates of other Scottish premieres. Clearly if a company is considering mounting a particular work such information is desirable. An authoritative statement such as 'the first Scottish performance for fifty years' can add an edge to promotion.

A dozen or so presentations - passing also as face-to-face promotion and selling - have been offered at academic conferences, or club and society meetings. Owners spoke at 'Previously...' the inaugural Edinburgh History Festival in 2011; twice in 2014 (Edinburgh and St Andrews) at what was now termed 'Previously...' Scotland's History Festival; and in 2015 to the Wagner Society of Scotland, and Friends of Scottish Opera. Further talks are scheduled.

Attempts were made to obtain interviews with arts correspondents of regional and national newspapers. On two or three occasions emails highlighting errors and omissions have been sent to opera reviewers, one receiving a handsome response (Clark 2010). 
In relation to performing arts and opera presence in the media, traditional press coverage and content seems to be melting away as a result of cutback after cutback. Arts writing in the form of interviews and previews seems to be one of the worst-hit areas, although this decline potentially creates opportunities for website development.

What other traditional marketing activity was tried? After initial efforts, the use of handing out flyers outsideperformancevenues has been discontinued. Many operagoers were in too much of a rush to tolerate a perceived interruption, either immediately before a performance or just afterwards.

In relation to access to new media, it is useful to be reminded of some fundamental issues. Internet penetration in the UK is touching 92\% ("Internet Access - Households and Individuals" 2016). Despite this growth there are still 10.2\% (5.3 million) who have never used the internet compared $w^{\text {ith }} \mathbf{1 1} .4 \%$ in 2015 . Age is a ralarant fartar here. Of OperaScotland website users, $36 \%$ are over 65 . In fact, many people in this target segment are expected to be significantly older than 65 , tending towards the mature and even, if the word can be used, old. (As an illustration, English Touring Opera in a recent research questionnaire used the age category 'over 80' rather than the more conventional and, in this case unhelpful, 'over 65' (Wise 2014).) This age category is likely to increase along with improved access to the web. Women aged 75 and over had seen the largest rise in recent internet use, up 169\% from 2011; however, still less than a third (32.6\%) were recent users in 2016. Initially we found that our Facebook work seemed to appeal more to women than men, while the database itself drew more men. But over time this distinction has narrowed. The reasons for this remain unclear.

\section{Reflection}

What other value has been created as a result of the website project? One of the unforeseen but positive outcomes is that personal relationships between the participants have been reinforced and intensified. At the start of the project all three co-founders could envisage retirement and the end of conventional employment. To initiate the website in parallel with the later phases of their employed lives was powerful in creating new identities for all three, both individual and collective, a role from which they cannot be sacked.

Marketing may have some magic in its appeal but there is nothing magical about achieving results. As Ruskin said of Turner, 'I know of no genius but the genius of hard work' (Bailey 2013). At a recent conference on new media someone referred to the process of building online communities as 'a slow burn...' OperaScotland was inaugurated partly with the thought that the website might be worth looking at in ten years' time. Seven years later in this process the founders are still using the same words.

Impact: what next?

OperaScotland lists performances within Scotland plus those of Scottish Opera and other Scottish companies (e.g. Opera Bohemia and the Denhof Company) where that company performed outside Scotland. A substantial number of towns and cities were once visited within England as well as overseas - including for example occasional performances in Portugal and Iceland. Clearly, a database which fails to incorporate similar activity across the UK and Ireland is of limited value when many opera companies travelled across the British Isles. Perhaps one day resources will permit more extension across England. Data from several significant and recently formed English companies might be relatively easy to incorporate. 
Analytics data offers great potential for understanding better the strengths and weaknesses of site promotion and use. This must be a major plank in future development of the site.

Then there is the issue of resource and developing critical mass with limited resources. As academics confronting entrepreneurial issues in what are new areas, the owners endorse the findings of others that the academic-practitioner gap is alive and well. (Brennan 2004; Brennan, Tzempelikos, and Wilson 2013). They have so far failed to identify many articles that would help managers in this sort of start up. Practitioners might point to the need for literature review articles, not least those written from a small enterprise perspective.

Level of resource has been a key issue. Having three core participants almost from the outset is considered critical to the steady progress of the site to date. From the motivational perspective, mutual support and encouragement can be offered and seems fundamental. Then again, meetings offer a forum to discuss ideas and manage anxiety. Gradually, clear and distinctive but complementary roles have developed. To simplify: of the three part time founders, one works as archivist and reviews; one networks and schedules; and the third manages new media and acts as editor. But resource constraints present an obvious challenge in what is a highly knowledge-intensive activity. Over the years the founders have been assisted by advice and insight from a number of consultants, people in business, and government business support agencies. The site has been presented as a live case study to a variety of student groups. Use of an intern in 2012 proved less successful although activity to recruit other contributors for specific tasks will continue. Efforts will be maintained to increase resources, develop collaborations and build traffic, engagement and impact.

The health of any opera community is dependent on external factors, specifically the quantity and quality of live opera provision. While grassroots professional opera subsidised largely by its young performers seems to be thriving, main stage performance at Scottish Opera and the Edinburgh International Festival is running at historically low levels (Clark 2015). Further budget cuts are in the pipeline. Under such circumstances, Friends Societies and similar organisations find it hard to thrive. Nevertheless they are considered potentially important sources of support (Hayes and Slater 2006; Slater 2010). While new arts forms emerge and arts attendance in general thrives, a long term decline in attendance at the elite performing arts has been noted (Kolb 2013).

The co-founders are aware that they have embarked on a process without end. There will always be additional information to track down, whether for forthcoming performances or in recovering data from the past. As more and more details of performances are logged, this is likely to become more challenging. As historical performances remaining to be found become more obscure, energies and attention might turn to obtaining supporting illustration and carrving out more interviews. There is scope also to develon the readabilitv of site material to better suit web users (Lindgaard et al. 2006). Other developments to enhance value for scholars will include communicating better the extent of the resources and making clear the source of the data (Warwick et al. 2008).

The use of analytics programs generates significant amounts of data that could be of value in interpreting new media use and in laying effective plans for site development. Researchers have found that owner managers of SMEs, while aware of the potential insights buried in this

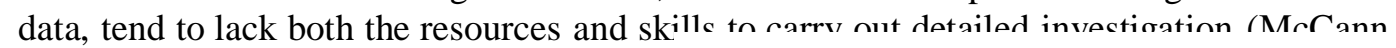
and Barlow 2015). OpScot is no exception. Significant time will be devoted to more detailed 
Higgins, C. (2011), "Theatre programmes and what to do with them", The Guardian, 23 February.

"Internet Access - Households and Individuals" (2016), ed. O. f. N. Statistics,

Kay, J. (2011), Obliquity - Why our goals are best achieved indirectly. Profile Books, London.

Keegan, S. (2011), Qualitative Research as Emergent Inquiry. Emergent Publications.

Kolb, B. M. (2013), "Using social media to enhance the customer attendance experience". In Routledge Companion To Arts Marketing, eds. D. O’Reilly, R. Rentschler and T. Kirchner, Routledge, London: 161-169.

Lindgaard, G., G. Fernandes, C. Dudek, and J. Brown, (2006), "Attention web designers: You have 50 milliseconds to make a good first impression", Behaviour \& Information Technology 25 (2):115-126.

Marini, F., (2008), "Performing Arts Archives: Dynamic Entities Complementing and Supporting Scholarship and Creativity", Theatre History Studies 28 (1):27-35.

McCann, M., and A. Barlow, (2015), "Use and measurement of social media for SMEs", Journal of Small Business and Enterprise Development 22 (2):273-287.

O'Reilly, D., (2011), "Mapping the arts marketing literature", Arts Marketing: An International Journal 1 (1):26-38.

Paul, W., (2015), Theatrical Producer: email communication, 23 November.

Plaza, B., (2011), "Google Analytics for measuring website performance", Tourism management 32 (3):477-481.

Plaza, B., P. G. Casimiro, M. P. M. Zuazo, and I. Ostolaza, (2011), "Validating Google analytics tips for micro-firms", African Journal of Business Management 5 (14):5681.

Reason, M., (2003a), "Archive or memory? The detritus of live performance", New Theatre Quarterly 19 (01):82-89. , (2003b), "Archive or memory? The Detritus of live performance", New Theatre Quarterly $19(73): 82$.

"REF impact" (2016), ed. H. E. F. C. f. E. (HEFCE),

Rentschler, R., and T. A. Kirchner, (2012), "Arts management/marketing journal citation analysis: assessing external impact", Arts Marketing: An International Journal 2 (1):6-20.

Ries, E. (2011), The Lean Startup: How Constant Innovation Creates Radically Successful Businesses. Portfolio Penguin, London.

Rudman, H. (2014), "Consultant: Discussion and progress review - OperaScotland", ed. I. Fraser,

Sarasvathy, S. D. (2012), "Effectuation and Entrepreneurship". In Enterprise and Small Business: Principles, Practice and Policy, eds. S. Carter and D. Jones-Evans, Pearson Education Ltd, Harlow: 135-151.

Shaw, E., (2004), "Marketing in the social enterprise context: Is it entrepreneurial?", Qualitative Market Research: An International Journal 7 (3):194-205.

Shaw, E. (2013), "Entrepreneurial Capital and Networks". In Entrepreneurial Marketing: A Global Perspective, eds. Z. Sethna, R. Jones and P. Harrigan, Emerald Group Publishing Limited Bingley: 147- 164.

Slater, A., (2010), "Understanding individual membership at heritage sites", International Journal of Culture, Tourism and Hospitality Research 4 (1):44-56.

Slater, A., and K. Armstrong, (2014), "Drivers and motives for membership at the Southbank Centre, a mixed arts venue in London, UK", International Journal of Nonprofit \& Voluntary Sector Marketing 19 (1):1-13. 
Stacey, R. D., and C. Mowles (2016), Strategic management and organisational dynamics: the challenge of complexity to ways of thinking about organisations. Pearson Education, Harlow.

Stone, R., (2004), "AusStage: recording Australian performing arts events". National Library of Australia News, pp. 5-7.

Twaddle, A. (2015), "The Battle of the U-boats (Episode 2)". In Scotland's War at Sea, BBC, Warrington, L., (2012), "Archiving New Zealand Theatre: TADB, The Theatre Aotearoa Database", Australasian Drama Studies:223.

Warwick, C., M. Terras, P. Huntington, and N. Pappa, (2008), "If you build it will they come? The LAIRAH study: Quantifying the use of online resources in the arts and humanities through statistical analysis of user log data", Literary and Linguistic Computing 23 (1):85-102.

Wise, K. (2014), "English Touring Opera - 'Opera in Cinemas' Report ", Guildhall School of Music and Drama, 


\section{Audience Overview}

$$
\begin{aligned}
& 2 \\
& 3 \\
& 4 \\
& 5 \\
& 6 \\
& 6 \\
& 0 v \\
& 8 \\
& 9
\end{aligned}
$$

\section{8}$$
3 \text { All Users }
$$

$100.00 \%$ Sessions

6 Overview

10 Sessions

11

$12^{5,000}$

13

14

15

16
17
18

18

19
20

21

228ssions

$23,23,487$

24

26

2

27 ages/Session

28
29
30
31
32

July 2014

January 2015

July 2015

January 2016

July 2016

New Visitor

Returning Visitor

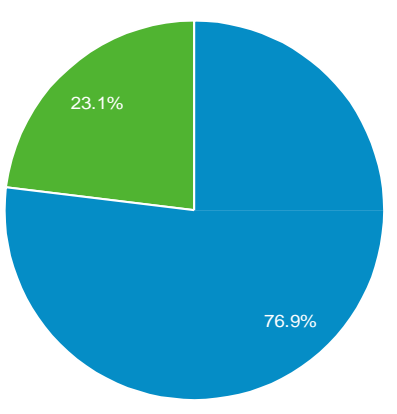

341,482

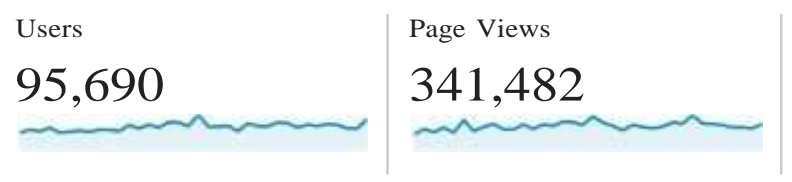

Avg. Session Duration

Bounce Rate

00:02:10

$74.72 \%$

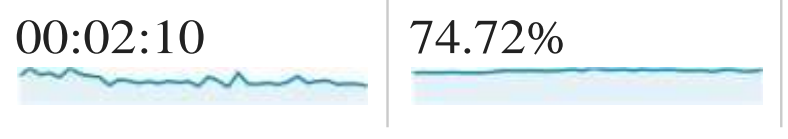

3
3
3
3
3
3
3
4

3
3
3
3
3
3

3

Country

Sessions \% Sessions

41

42

43

4

45

46

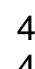

4

4

49

5

5

52

5

5

54

56

57

58

59

60 